\title{
Erythroid Maturation Index
}

National Cancer Institute

\section{Source}

National Cancer Institute. Erythroid Maturation Index. NCI Thesaurus. Code C135415.

The determination of the ratio of the sum of erythroid maturation phase cells (pool) to the sum of erythroid proliferative phase cells (pool) present in a sample. 